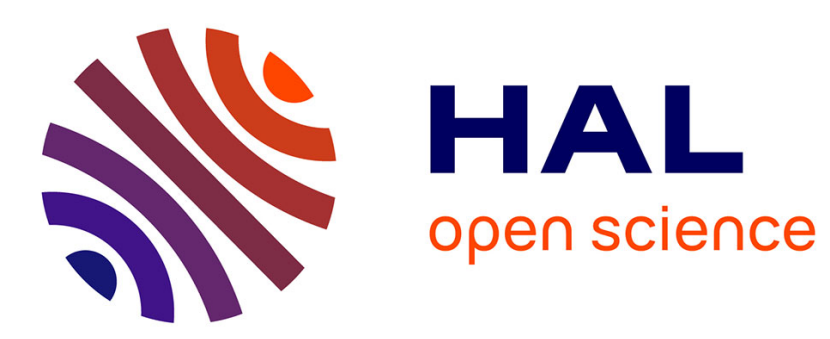

\title{
An active control concept for the TALC space telescope
} Christophe Collette, Simon Chesne, Sébastien Correia, Gilles Durand

\section{To cite this version:}

Christophe Collette, Simon Chesne, Sébastien Correia, Gilles Durand. An active control concept for the TALC space telescope. CFM 2015 - 22ème Congrès Français de Mécanique, Aug 2015, Lyon, France. hal-03446509

\author{
HAL Id: hal-03446509 \\ https://hal.science/hal-03446509
}

Submitted on 24 Nov 2021

HAL is a multi-disciplinary open access archive for the deposit and dissemination of scientific research documents, whether they are published or not. The documents may come from teaching and research institutions in France or abroad, or from public or private research centers.
L'archive ouverte pluridisciplinaire HAL, est destinée au dépôt et à la diffusion de documents scientifiques de niveau recherche, publiés ou non, émanant des établissements d'enseignement et de recherche français ou étrangers, des laboratoires publics ou privés. 


\title{
An active control concept for the TALC space telescope
}

\author{
C.COLLETTE ${ }^{a}$, S. CHESNE ${ }^{b}$, S. CORREIA ${ }^{b}$, G. DURAND $^{c}$ \\ a.Université Libre de Bruxelles, BEAMS department, 50, av. F.D. Roosevelt, 1050 Brussels \\ (Belgium). Christophe.collette@ulb.ac.be \\ b. Université de Lyon, CNRS INSA-Lyon, LaMCoS UMR5259, F-69621(France). \\ simon.chesne@insa-lyon.fr \\ c. CEA Saclay, DSM-IRFU-SAP, 91191 Gif sur Yvette cedex (France).durandgs@cea.fr
}

\section{Résumé :}

Cet article présente un modèle dynamique simplifié du télescope de TALC. Malgré sa simplicité, il est représentatif d'une partie de la dynamique du système, qui ont permis l'élaboration de stratégies de contrôle préliminaires pour amortir les résonances du système. En utilisant des câbles actifs, il a été montré que les résonances peuvent être amorties de façon significative, et que l'autorité du contrôle augmente avec le nombre de câbles actifs. En outre, il a été montré que, même avec une faible valeur du gain de commande, la valeur efficace d'une grandeur représentative du chemin optique peut être réduite par un facteur trois.

\begin{abstract}
:
The paper presents a simplifieddynamical model of the TALC telescope.Even though the model is simple, it represents partially the system dynamics, which allowed elaborating preliminary control strategies to damp system resonances.Using active cables, it has been shown that the resonances can be significantly damped, and that the control authority increases as a function of the number of active cables. Additionally, it has been shown that, even with a low value of the control gain, the RMS value of a quantity representative of the optical path difference can be reduced by a factor three.
\end{abstract}

\section{Mots clefs :Space telescope, active cable, structural damping}




\section{Introduction}

Further space exploration in the far-infrared requires larger telescopes, in order to improve the spatial resolution of captured images. To this purpose, the Thinned Aperture Light Collector (TALC) concept has been recently proposed [1,2], which offers novel perspectives for deep space explorations. A conceptual design of TALC is shown in Fig. 1 (left). The general structure is one of a bicycle wheel, where the inner side of the segments in compression to each other plays the role of the rim. The segments are linked to each other using a pantograph scissor system that let the segments extend from a pile of mirrors to a parabolic ring keeping high stiffness at any time during the deployment. The inner corners of the segments are linked to a central axis using spikes as in a bicycle wheel.The primary mirror has an external diameter of $20 \mathrm{~m}$. Thanks to an original folding concept, it can be stored in the fairing of Ariane 6 during the flight, then deployed in space.

In this paper, we present a simplified model of the telescope, using lumped masses connected by springs. Even thought the model discussed is extremely simple, it already contains interesting features of the telescope dynamics, allowing elaborating control strategies for damping structural vibrations, and for controlling the shape of the primary mirror at its very first resonance frequencies.

The paper is structured as follows. Section two describes the simplified model, section three presents the control approach, section four shows an example of the control performance, expressed in terms of the optical path difference, and section five draws the conclusions.

\section{Simplified model of TALC}

The simplified lumped-mass model of TALC isshown in Fig. 1(right). The mass of the vertical beam, $m_{b}=100 \mathrm{~kg}$, has been equally distributed on the three masses $m_{1}, m_{2}$ and $m_{3}$. It represents a 16 meters length tube of carbon, with a diameter of $0.35 \mathrm{~m}$ and a thickness of $4 \mathrm{~mm}$. The mass of the primary mirror is equally distributed on two masses $\mathrm{m}_{4}$ and $\mathrm{m}_{5}$. Each mass moves only in the horizontal direction.

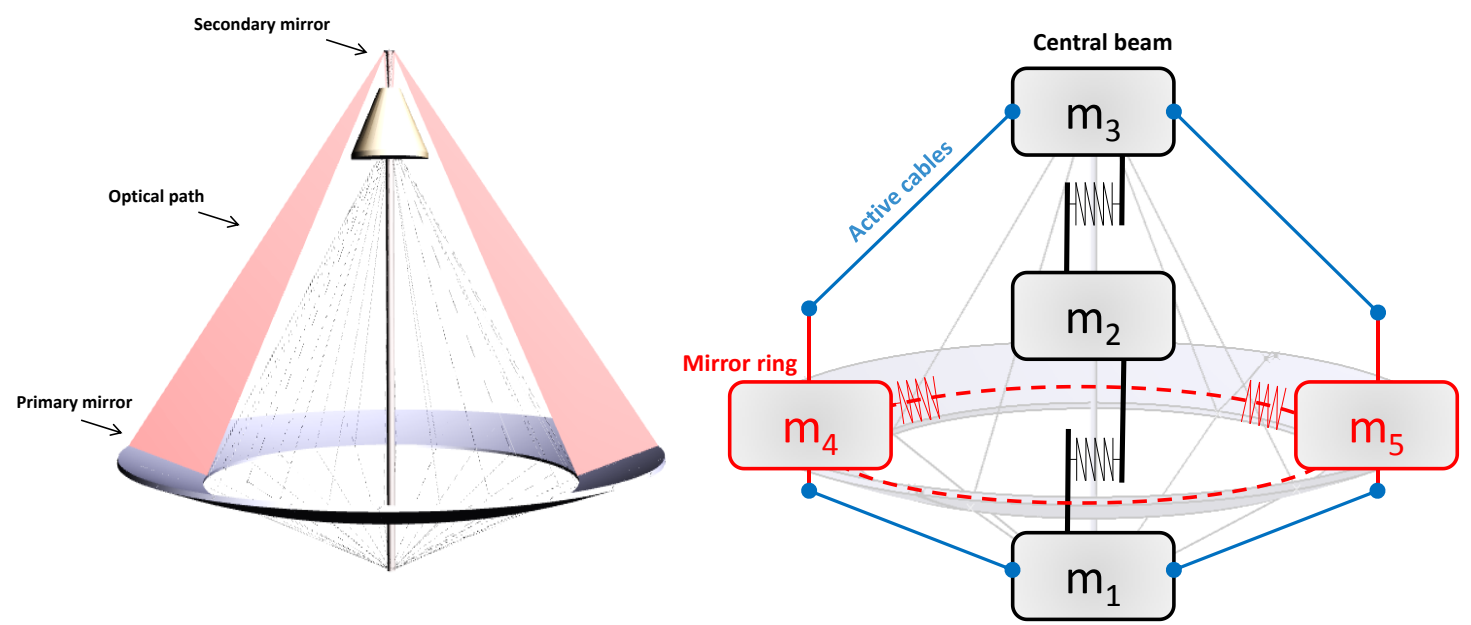

Figure 1 Conceptual design of the TALC (left) and simplified lumped mass model (right). 
Additionally, $\mathrm{m}_{2}$ includes the mass of a telescopic arm $\left(\mathrm{m}_{\mathrm{s}}=30 \mathrm{~kg}\right)$, whichconnects the telescope to the satellite at the middle of the central boom. The upper mass $m_{3}$ includes the mass of the optics, taken as $\mathrm{m}_{\mathrm{o}}=750 \mathrm{~kg}$. The numerical values of the masses have been chosen as follows: $\mathrm{m}_{1}=\mathrm{m}_{\mathrm{b}} / 3 ; \mathrm{m}_{2}=\mathrm{m}_{\mathrm{b}} / 3+\mathrm{m}_{\mathrm{s}}$; $\mathrm{m}_{3}=\mathrm{m}_{\mathrm{b}} / 3+\mathrm{m}_{\mathrm{o}} ; \mathrm{m}_{4}=\mathrm{m}_{5}=900 \mathrm{~kg}$ (the mirror ring is a combination of 18 mirrors of $100 \mathrm{~kg}$ ). The stiffness of the springs connecting $\mathrm{m}_{1}, \mathrm{~m}_{2}$ and $\mathrm{m}_{3}$ have been chosen to get a first flexible mode of the beam around $8.2 \mathrm{~Hz}$, where $\mathrm{m}_{2}$ moves in opposite phase with the other ones, to fit with the first bending mode of this part of the structure. The stiffness of the cables is $k_{c}=2.8 \mathrm{MN} / \mathrm{m}$, and the stiffness of the piezoelectric actuators is taken as $\mathrm{k}_{\mathrm{a}}=20 \mathrm{MN} / \mathrm{m}$. These values are typical values found in the literature. The stiffness between $m_{4}$ and $m_{5}$ is tuned as $k_{m}=150 \mathrm{kN} / \mathrm{m}$, in order to obtain a first flexible mode of the mirror around $3 \mathrm{~Hz}$, as found from a previous finite element study [3]. Finally, a modal damping of $0.1 \%$ has been assigned to all the modes.

Figure 2 shows an example of transmissibility between the mass $m_{3}$, representing the top of the central boom where the optics is located, and the middle mass $\mathrm{m}_{2}$, where the telescope is attached to the satellite. The figure shows that the transmissibility is dominated by two peaks. The first one, at 0.76 $\mathrm{Hz}$, corresponds to a motion of $\mathrm{m}_{2}$ out of phase with the rest of the structure; the second one, at 15.1 $\mathrm{Hz}$, corresponds to a motion of $\mathrm{m}_{3}$ out of phase with the rest of the structure.

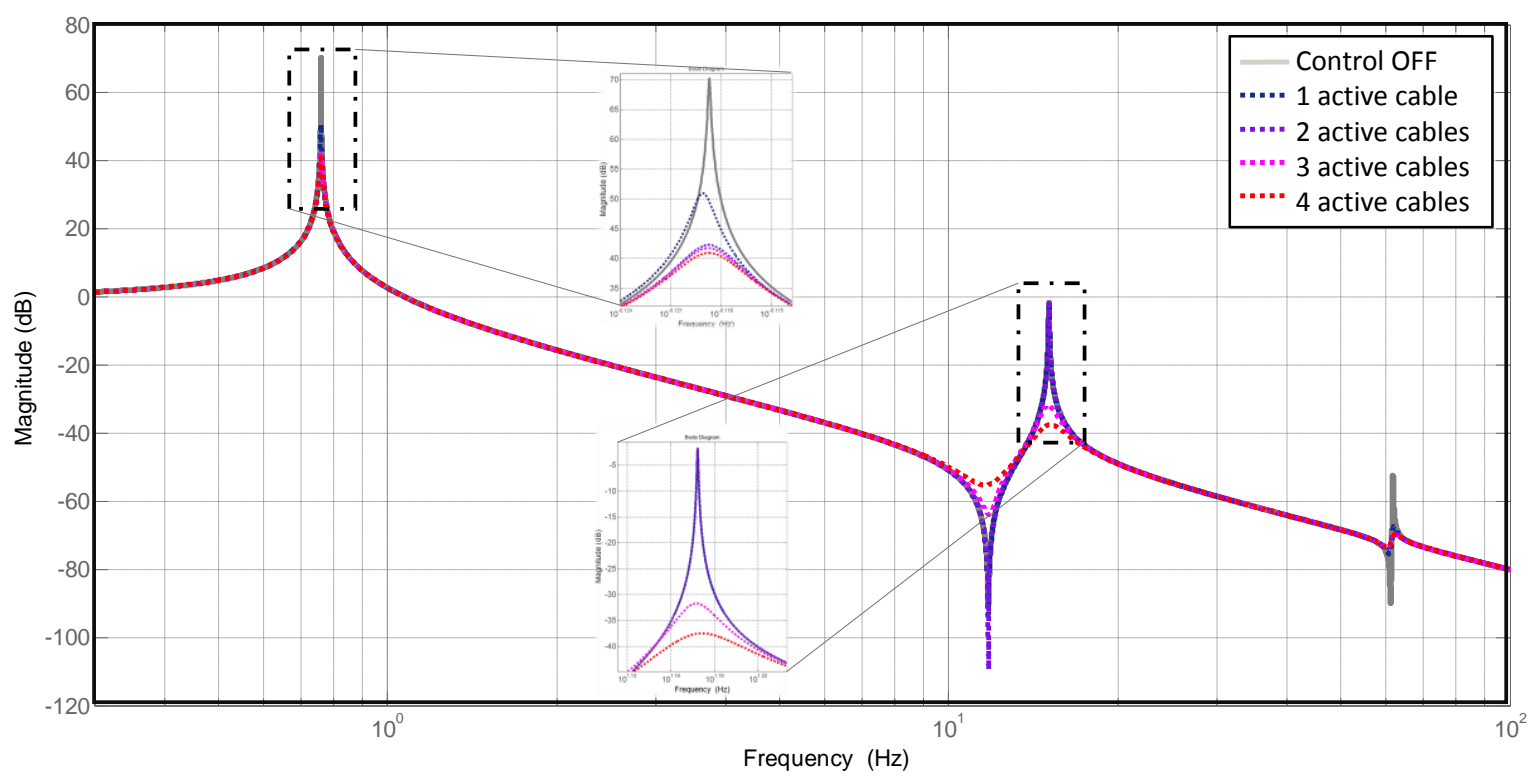

Figure 2 Transmissibility $\left(\mathrm{x}_{3} / \mathrm{x}_{2}\right)$ between the mass $\mathrm{m}_{3}$, where is optics is located, and the middle mass $\mathrm{m}_{2}$, where the telescope is attached to the satellite.

In the following section we will study the possibility to damp these peaks with an active control of the telescope vibrations in order to reduce the sensitivity of the optical path difference (represented by $\mathrm{x}_{3^{-}}$ $\mathrm{x}_{4}$ ) to external disturbances.

\section{$3 \quad$ Active damping with piezoelectric tendons}

The strategy considered in this section takes advantage of the cables to act directly on the telescope dynamics. Basically, we propose to equipsome of the cables with active tendons, constituted of a piezoelectric actuator in series with a force sensor, as shown in Fig. 3. Through this embodiment, we can use decentralized loops in each active tendon, which have the interesting property to be unconditionally stable. Such a strategy has already been successfully applied to other large structures, e.g. for particle collider [4] or gravitational wave detector [5]. The details of the control strategy can be found in these references, and an improvement of the strategy can be found here [6]. One can notice 
that it is also foreseen to use the actuators for controlling the shape of the mirror, i.e. the distance and orientation of each segment. However, this latter functionality is not studied in this paper, which focuses only on active damping.

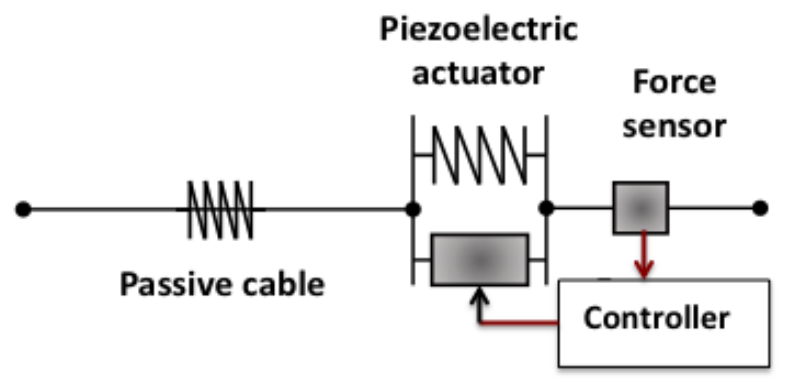

Figure 3 Scheme of an active cable.

Figure 4 shows an example of results obtained on the transmissibility $\mathrm{x}_{3} / \mathrm{x}_{2}$. The active cables have a clear authority on both peaks, which is increasing as a function of the number of active cable. For clarity, an equivalent modal damping factor for both peaks is shown in Fig. 4 as a function of the number of active cable. As one could have anticipated, the damping factor of both modes increases with the number of active cables, while taking always the same controller for all the cables. The control gain has been taken intentionally very low as we aim to illustrate a control strategy, rather than finding the optimal values. One can observe that two cables have no authority on the second resonance. This is obviously due to the shape of the mode which does not strain these cables.

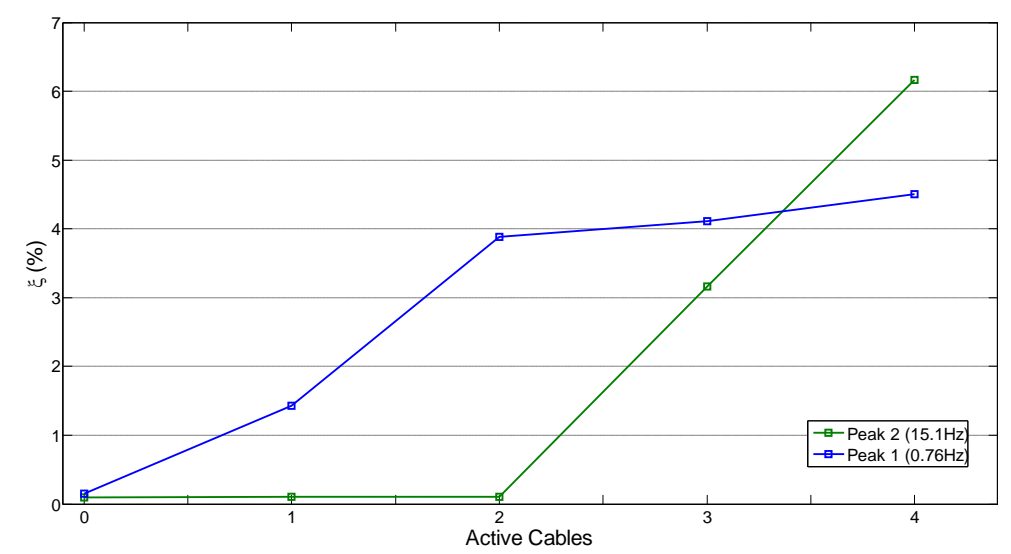

Figure 4Damping factor of the two poles dominating the transmissibility (Fig. 2) as a function of the number of active cables.

\section{$4 \quad$ Impact on Optical Path Difference}

As the main goal of the active stabilization of the telescope is to ensure high quality images, we have tested the impact of the proposed controller on $\mathrm{x}_{3}-\mathrm{x}_{4}$, assumed as a quantity representative of the Optical Path Difference (OPD). Figure 5 shows the transmissibility between $\mathrm{x}_{3}-\mathrm{x}_{4}$ and $\mathrm{x}_{2}$, which is the motion of the anchorage point of the telescope on the satellite. The curve shows again two peaks, corresponding to the two peaks which are visible in Fig. 2. The solid curve has been obtained when the controller is turned OFF, and the dashed red curve has been obtained with four active cables, and the same controller as in section 2. 


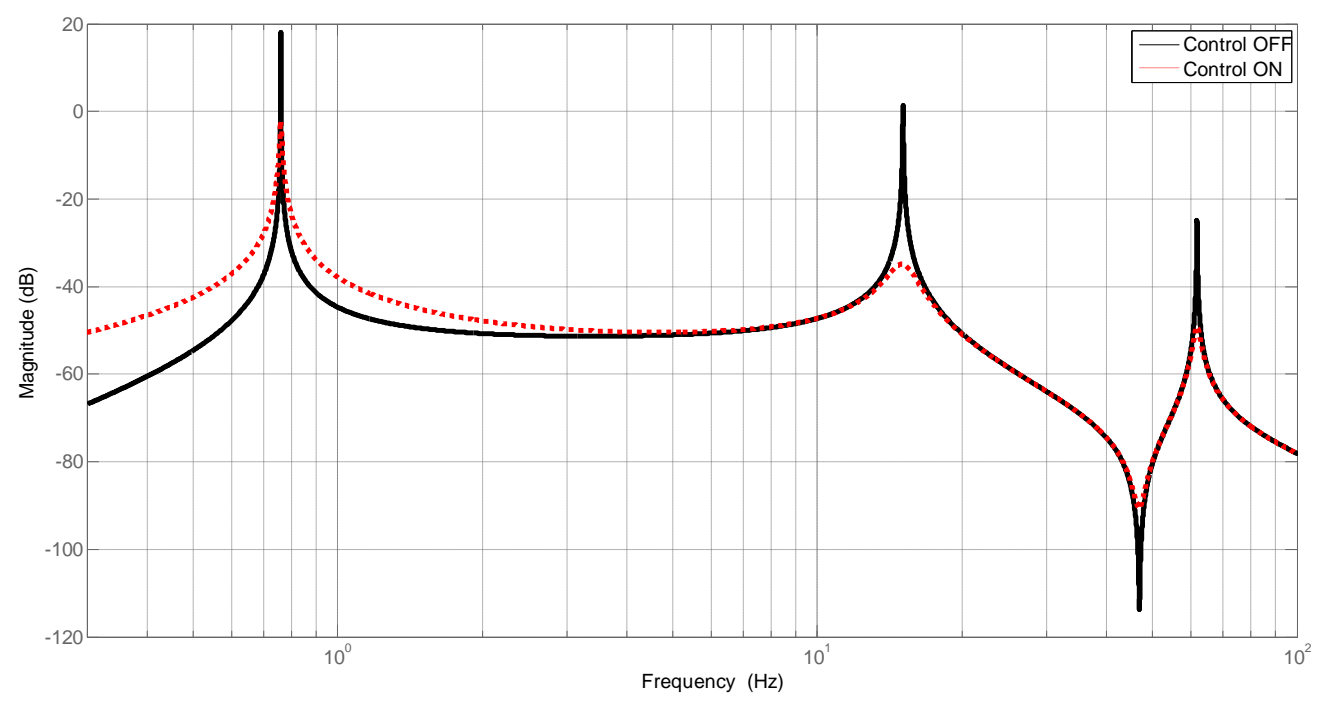

Figure 5 Transmissibility between $\left(\mathrm{x}_{3}-\mathrm{x}_{4}\right)$, representing the optical path difference (OPD) and the motion of the centre of the boom ( $\left.\mathrm{x}_{2}\right)$, when the control of the cables is turned OFF and turned ON with four active cables.

One sees that the reduction of the overshoots has been obtained at the cost of a slight degradation at low frequency, indicative of a softening of the feedback operation. In order to further estimate the effect of the controller on the OPD, we have calculated the response of the system to an input motion at $\mathrm{x}_{2}$, whose power spectral density has been chosen arbitrarily as $1 \mathrm{~mm}^{2} / \mathrm{Hz}$. Figure 6 shows the integrated RMS value of $\mathrm{x}_{3}-\mathrm{x}_{4}$ when the controller turned OFF (black curve) and turned ON (dashed red curve).

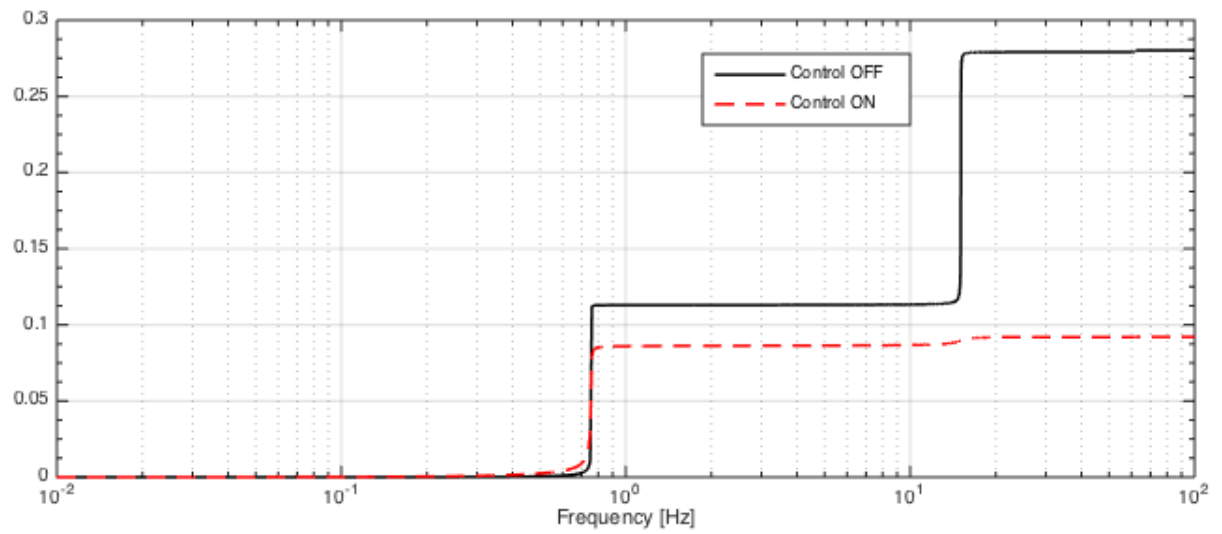

Figure 6 Integrated RMS value of the optical path difference $\left(\mathrm{x}_{3}-\mathrm{x}_{4}\right)$ when the controller is turned OFF and turned $\mathrm{ON}$ with four active cables. Adisplacement of $1 \mathrm{~mm}^{2} / \mathrm{Hz}$ of the central mass $\mathrm{m}_{2}$ has been taken as input excitation.

Without control, one sees that the contributions to the RMS are mainly due to the two peaks, creating two steps in the cumulated RMS. With control, the total RMS is reduced by a factor three, due to the increase of structural damping. 


\section{Conclusion}

In this paper, we have presenteda simplified analytical model of the TALC telescope which contains only fived.o.f. Even though the model is over-simplified on many aspects, it already contains some interesting features of the system dynamics, which allowed elaborating preliminary control strategies. In particular, we have studied the possibility to damp system resonances using active cables. It has been shown that the control strategy allow to control the peaks, and that the authority increases as a function of the number of active cables. Additionally, it has been shown that, even with a low value of the control gain, the RMS value of a quantity assumed as representative of the OPD can be reduced by a factor three.

In the near future, it is planned to test the proposed strategy on a more realistic model of the telescope dynamics.

\section{References}

[1] G. Durand, M. Sauvage, A. Bonnet, L. Rodriguez, S. Ronayette, P. Chanial, L. Scola, V. Révéret, H. Aussel, M. Carty, M. Durand, L. Durand, P. Tremblin, E. Pantin, M. Berthe, J. Martignac, F. Motte, M. Talvard, V. Minier, P.Bultel, TALC: a new deployable concept for a $20 \mathrm{~m}$ far-infrared space telescope, Proc. SPIE 9143, Space Telescopes and Instrumentation 2014: Optical, Infrared, and Millimeter Wave, 9143-41, 2 August 2014.

[2] M. Sauvage, G. Durand,L. Rodriguez, P. Chanial, J.-L. Starck, S. Ronayette, H. Aussel, V. Minier, F. Motte and E. Pantin, The Science case and data processing strategy for thinned aperture light collector: a project for $20 \mathrm{~m}$ far infrared space telescope, Proc. SPIE 9143, Space Telescopes and Instrumentation 2014: Optical, Infrared, and Millimeter Wave, 9143-42, 2 August 2014.

[3] A. Bonnet, Le télescope TALC : Contrôle en position des miroirs Amortissement des vibrations, rapport interne INSA, 2013.

[4] C. Collette, D. Tshilumba, L. Fueyo-Rosa and I. Romanescu, Conceptual design and scaled experimental validation of an actively damped carbon tie rods support system for the stabilization of future particle collider superstructures, Review of Scientific Instruments, 2013, vol.84(2), 023302.

[5] D. Tshilumba, L. Nuttal, T. Mac Donald, R. Mittelmann, B. Lantz, F. Matichard and C. Collette, Vibration analysis and control of the LIGO observatories large chambers and support piers, proceedings of the ISMA conference, September 2014, (Leuven, Belgium).

[6] S. Chesne, A. Milhomem, C. Collette, Enhanced active damping of flexible structures with inherently stable power ports, 22nd International congress on sound and vibration, 12-16 July 2015 (Florence, Italy). 